\title{
The Epidemiology of Knee Arthroscopy during Coronavirus Disease 2019 Pandemic
}

\author{
Asep Santoso ${ }^{1,2 *}$ (D), Iwan Budiwan Anwar ${ }^{1,2}$, Tangkas SMHS Sibarani ${ }^{1,2}$, Pamudji Utomo ${ }^{1,2}$, Zarkasyi Arimukti ${ }^{1}$, Ibnu Yudistiro ${ }^{1}$, \\ Muhammad Abdul Hamid ${ }^{1}$ \\ ${ }^{1}$ Department of Orthopaedic and Traumatology, Universitas Sebelas Maret, Surakarta, Indonesia; ${ }^{2}$ Division of Adult \\ Reconstructive Surgery and Sport Injury, Prof. Dr. R. Soeharso Orthopaedic Hospital, Surakarta, Indonesia
}

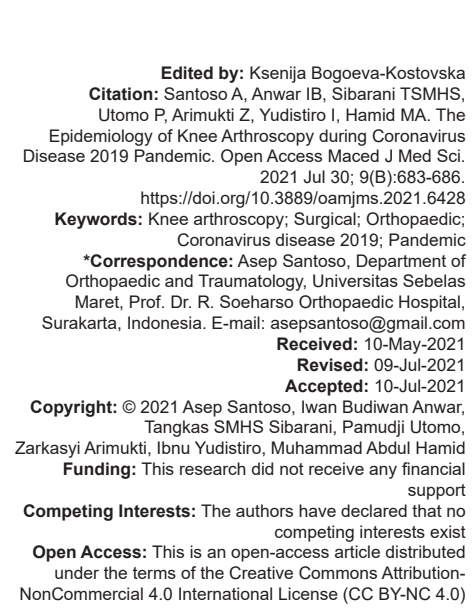

Introduction

Coronavirus disease 2019 (COVID-19) pandemic caused by the severe acute respiratory syndrome coronavirus 2 (SARS-Cov-2) has made a huge impact on global health services including in orthopedic surgical service [1], [2]. Trauma and orthopedics is a key specialty where operations will be required to continue despite a patient's COVID-19 status [3]. However, orthopedic practice could not remain unaffected under these unforeseen circumstances. Non-urgent consultations and many surgical procedures were canceled or postponed [4], [5], [6]. Elective surgery in many institutions was suspended, and the overall orthopedic case volume dropped dramatically [7], [8]. The change in orthopedic surgical service includes all aspects in orthopedic from trauma to elective surgical service [8].

Knee surgery (including arthroscopy) is one of the emerging surgical services in Indonesia [9]. Many centers have the facility to perform knee arthroscopy procedures recently. Since the first case of COVID-19 has been announced in Indonesia at March 2020, all aspect of orthopedic service has been affected [10], [11], [12]. As the pandemic goes on, some of the patients prefer to postpone or cancel the surgery planning. However, regarding the risk of further problems/complications, if the surgery is delayed, some of the patients still prefer to receive knee arthroscopy surgical service. In the recent study, we tried to evaluate the epidemiology of knee arthroscopy procedures during the COVID-19 pandemic at our institution. We hypothesized that there are some changes in the pattern and epidemiology of knee arthroscopy compared to the non-pandemic era.

\section{Materials and Methods}

Retrospective data collection was performed on all patients who received knee arthroscopy procedures at Prof dr. R. Soeharso Orthopaedic Hospital, Surakarta, Indonesia during the year 2020. The study evaluated the demographic data, the indication of surgery, and trends 
of the number of surgeries according to period time. This study also compared the data of knee arthroscopy procedures performed during the corresponding period before the pandemic in Indonesia (January to December 2019). All knee arthroscopy procedure was done by a single surgeon (AS).

Pre-operative screening at the outpatient clinics was performed on all patients who will receive knee arthroscopy include history and clinical examination, laboratory examination, chest radiograph, rapid COVID-19 test, and polymerase-chain-reaction (PCR) swab test. The internist performed the decision to proceed with elective surgery at our institution. Patients with confirmed COVID-19 based on PCR swab were postponed to have surgery and treated accordingly. Knee arthroscopy was performed under spinal anesthesia and tourniquet control.

Complete personal protective equipment (PPE) was used by all operating theater personal during the procedure. We used recommended PPE included surgical gowns, face shields or goggles, double gloves, and FFP2-3 or N95-99 respirator masks. N95 respirator mask used to prevent the potential to aerosolize the virus during aerosol producing procedures. A Head cap, gown, and gloves are used to prevent contact with a contaminated surface or biological liquid. The length of stay of the patient post-operatively was limited to 2-3 days. Further post-operative rehabilitation was performed through an outpatient clinic.

\section{Results}

There was a total of 88 knee arthroscopy surgery performed during the period January to December 2020. The patients mean age was 30.8 years old (range 14-75) with 64 male patients and 24 female patients. While during 2019, there were only 28 knee arthroscopy surgeries in our hospital with mean patients age 29.5 years old (range 17-57). There was a decrease in the number of knee arthroscopy during April and May 2020. However, it is increased from June to October 2020. The decreasing number of surgeries also occurred in November 2020 which was later followed by an increasing number of surgeries in December 2020 (Figure 1).

The most common procedure performed during knee arthroscopy in 2020 was anterior cruciate ligament reconstruction (ACLR) which was performed in 53 of 88 cases $(60.2 \%)$. Followed by meniscus repair/meniscectomy in $21 / 88$ cases $(23.8 \%)$ and posterior cruciate ligament reconstruction (PCLR) in $11 / 88$ cases $(12.5 \%)$. While another procedure includes debridement, diagnostic, and cartilage/fracture treatment were only $9 / 88$ cases $(10.2 \%), 2 / 88$ cases $(2.2 \%)$, and $4 / 88$ cases $(4.5 \%)$, respectively. The

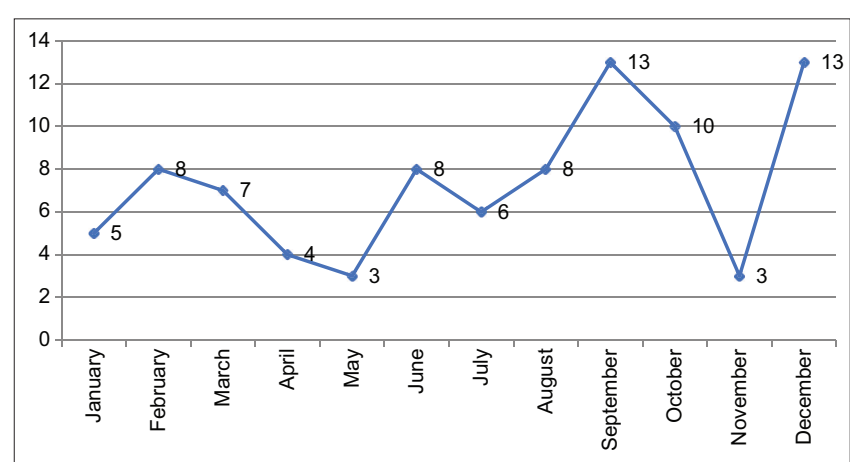

Figure 1: Distribution of knee arthroscopy surgery by months during pandemic (January - December 2020)

pattern was almost similar during 2019 which ACLR was the most commonly performed procedure (17/28, $60.7 \%)$, followed by PCLR $(7 / 28,25 \%)$ and procedure for meniscus $(9 / 28,32 \%)$ (Figure 2$)$.

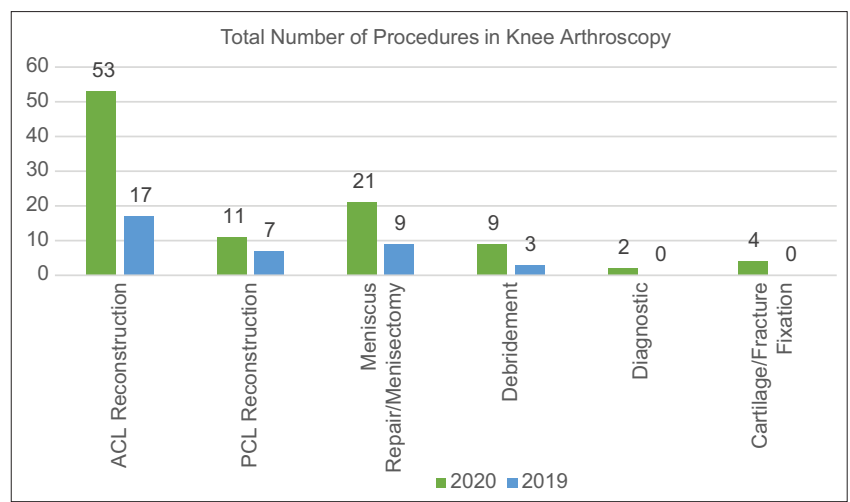

Figure 2: Total number of procedures during knee arthroscopy in 2020 and 2019

Among ACL reconstruction cases in 2020, 30 of $53(56.6 \%)$ was an isolated ACLR, while the rest 23 cases $(43.4 \%)$ were a combined procedure with either collateral ligament reconstruction or meniscus procedure. A similar condition also occurred to PCLR in 2020, where Isolated PCLR was more commonly performed in $7 / 11$ cases $(63.6 \%)$ compared to combined PCLR in $4 / 11$ cases (36.4\%). The condition was different with 2019, where most of ACLR were a combined procedure $(12 / 17,70.6 \%)$ compared to isolated ACLR in 5 of 17 cases (29.4\%). Procedure for meniscus was more commonly performed in combination with another procedure both in 2020 and 2019, 12/21(57\%) and $8 / 9(88.8 \%)$, respectively (Figure 3). Among all patient received knee arthroscopy during 2020, none have post-operative complication or infection due to SARS-Cov-2.

\section{Discussion}

Orthopedic practice has been profoundly revolutionized by the pandemic. In Europe, a drastic 


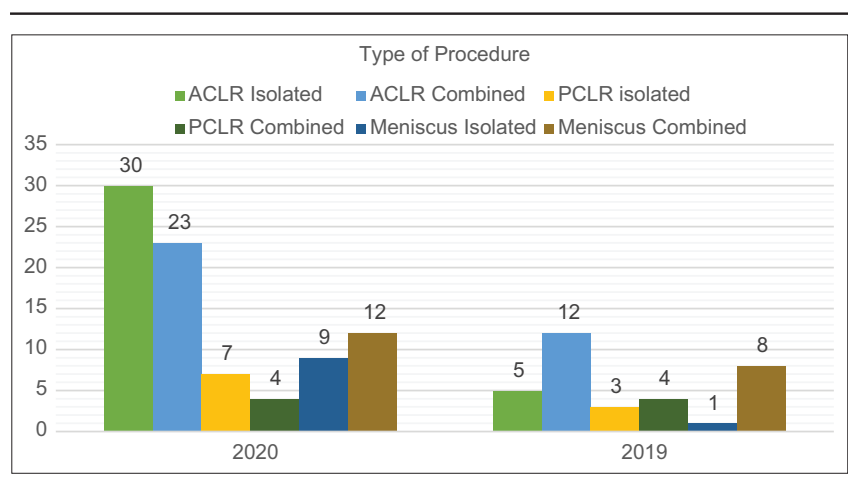

Figure 3: Type of procedures for anterior cruciate ligament reconstruction, posterior cruciate ligament reconstruction, and Meniscus during knee arthroscopy during pandemic (January December 2020)

cutback in orthopedic surgical procedures was documented [8]. Similar conditions also occurred in Indonesia [7], [12]. Arthroscopic procedure that categorized in elective surgery was also affected [8], [13]. However, no clear data on the impact of the COVID-19 pandemic on arthroscopy service in Indonesia until recently. To our knowledge, this is the first study to explain the epidemiology of knee arthroscopy during the COVID-19 pandemic from Indonesia.

The number of knee arthroscopy during 2020 was still higher compared to 2019. This is mainly due to the trend of an increasing number of patients visiting our hospital each year from 2014 to 2020. Arthroscopy service in our hospital was re-started in early 2018 after a long-term vacuum. Therefore, 2019 was still the year of hospital promotion for arthroscopy service. The condition was similar to the results from a study by Kazubski et al. in Poland which showed that the COVID-19 pandemic did not reduce the number of arthroscopies performed at their center and the mean age of the patients did not change [14].

COVID-19 cases in Indonesia has first announced in early March 2020 [10]. This situation explains the decrease in the number of surgeries during April and May 2020, as most elective surgical procedures were postponed for the mitigation and control of spreading of COVID-19. Another decrease in the number of surgeries was in November 2020, this is due to the performing surgeon was confirmed for SARS-Cov-2 infection. The surgeon was advised for rest and hospitalization for around 2 weeks.

ACLR was the most common procedure performed during knee arthroscopy. During the pandemic era (2020) isolated ACL reconstruction was more commonly performed compared to the combined procedure. This indicates that during the pandemic, a simpler surgery was more preferred compared to a more complex combined surgery. This condition was different from the condition before the pandemic era, where combined surgical procedure was more commonly performed during knee arthroscopy.

According to the guidelines proposed by local institutions and international societies, including the American Academy of Orthopaedic Surgeons elective surgeries should be judiciously postponed depending on the local prevalence of COVID-19 and resource availability (PPE, ICU beds, respirators, and personnel) [15]. A high standard of care during the COVID-19 pandemic needs to ensure in the management of surgical patients. However, choosing which surgeries to postpone is not easily determined without some controversy [16], [17]. We evaluate whether it is possible to postpone surgical treatment until the patient is no longer considered potentially infectious or at risk of perioperative complications. Resuming elective surgical procedure need comprehensive preparation [18]. In our hospital, the decision to resume elective surgical service include arthroscopy was performed in collaboration with the internal medicine department after complete screening for SARS-Cov-2 infection.

\section{Conclusion}

There was some difference in the epidemiology of knee arthroscopy during the COVID-19 pandemic compared to the non-pandemic era. Comprehensive preoperative screening is needed before resume elective surgical service.

\section{References}

1. Budhiparama NC, Rhatomy $S$, Santoso A. The inaugural issue of the hip and knee journal. Hip Knee J. 2020;1(1):1-3. https:// doi.org/10.46355/hipknee.v1i1.29

2. Haleem A, Javaid M, Vaishya R, Vaish A. Effects of COVID-19 pandemic in the field of orthopaedics. J Clin Orthop Trauma. 2020;11(3):498-9. https://doi.org/10.1016/j.jcot.2020.03.015 PMid:32405218

3. Velavan TP, Meyer CG. The COVID-19 epidemic. Trop Med Int Health. 2020;25(3):278-80. https://doi.org/10.1111/tmi.13383 PMid:32052514

4. Faria G, Onubogu IK, Tadros BJ, Relwani J. Change in practice due to COVID-19 early experiences of a United Kingdom district general hospital in trauma and orthopaedics. J Orthop 2020;22:288-90. https://doi.org/10.1016/j.jor.2020.06.004 PMid:32565644

5. Al-Jabir A, Kerwan A, Nicola M, Alsafi Z, Khan M, Sohrabi C et al. Impact of the coronavirus (COVID-19) pandemic on surgical practice Part 2 (surgical prioritisation). Int J Surg. 2020;79(1):233-48. https://doi.org/10.1016/j.ijsu.2020.05.002 PMid:32413502

6. lyengar KP, Jain VK, Vaish A, Vaishya R, Maini L, Lal H. Post COVID-19: Planning strategies to resume orthopaedic surgery -challenges and considerations. J Clin Orthop Trauma. 2020;11(Suppl 3):S291-5. https://doi.org/10.1016/j. jcot.2020.04.028 
7. Santoso A, Persada G, Anwar IB, Sibarani TS, Mariyanto I, Utomo P. Effect of coronavirus disease-19 pandemic to the volume of total hip and knee arthroplasty surgical service: Experience from a single tertiary orthopedic hospital in Indonesia. Open Access Maced J Med Sci. 2020;8:642-5. https://doi.org/10.3889/oamjms.2020.5652

8. Liebensteiner MC, Khosravi I, Hirschmann MT, Heuberer PR, Board of the AGA-Society of Arthroscopy and Joint-Surgery; M Thaler 1. Massive cutback in orthopaedic healthcare services due to the COVID-19 pandemic. Knee Surg Sports Traumatol Arthrosc. 2020;28(6):1705-11. https://doi.org/10.1007/s00167-020-06032-2 PMid:32356047

9. Djaja YP, Prasetia R, Santoso A, Rahyussalim AJ, Mustamsir E, Dilogo $\mathrm{IH}$. A decade of evolution in Indonesian orthopedic publication: A bibliographic report. J Clin Orthop Trauma. 2020;15:110-6. https://doi.org/10.1016/j.jcot.2020.10.016 PMid:33717924

10. Setiawaty V, Kosasih H, Mardian Y, Ajis E, Prasetyowati EB, Siswanto, et al. Sars-CoV-reference laboratory ministry of health Indonesia. The identification of first COVID-19 cluster in Indonesia. Am J Trop Med Hyg. 2020;103(6):2339-42. https:// doi.org/10.4269/ajtmh.20-0554 PMid:33069265

11. Rhatomy S, Phatama KY, Rasyid FA, Mustamsir E. Changes in orthopedic services in two Indonesian tertiary-referral hospitals during the coronavirus-19 pandemic. Open Access Maced J Med Sci. 2020;8(T1):538-41. https://doi.org/10.3889/ oamjms.2020.5491

12. Phatama KY, Rhatomy S, Santoso A. Budhiparama NC. The pandemic hits us hard, but we don't lose hope. Hip Knee J. 2021;2(1):1-4. https://doi.org/10.46355/hipknee.v2i1.72

13. Goyal T, Harna B, Taneja A, Maini L. Arthroscopy and COVID-19: Impact of the pandemic on our surgical practices. J Arthrosc Joint Surg. 2020;7(2):47-53. https://doi.org/10.1016/j. jajs.2020.06.008

14. Kazubski K, Tomczyk Ł, Morasiewicz P. Effects of the COVID-19 Pandemic on the Epidemiology of Knee and Shoulder Arthroscopy Procedures in a University Hospital Department in Poland. Research Square; 2021. https://doi.org/10.21203/ rs.3.rs-146656/v1

15. Guy DK, Bosco JA $3^{\text {rd }}$. SIF AAOS Guidelines for Elective Surgery During the COVID-19 Pandemic; March 31. https://www.aaos. org/globalassets/about/covid-19/aaos-guidelines-on-electivesurgery.pdf [Last accessed on 2020 Apr 19].

16. Ambrosio L, Vadalà G, Russo F, Papalia R, Denaro V. The role of the orthopaedic surgeon in the COVID-19 era: Cautions and perspectives. J Exp Orthop. 2020;7(1):35. https://doi. org/10.1186/s40634-020-00255-5

PMid:32458150

17. DiazA, SaracBA, SchoenbrunnerAR, Janis JE, PawlikTM. Elective surgery in the time of COVID-19. Am J Surg. 2020;219(6):900-2. https://doi.org/10.1016/j.amjsurg.2020.04.014 PMid:32312477

18. Massey PA, McClary K, Zhang AS, Savoie FH, Barton RS Orthopaedic surgical selection and inpatient paradigms during the coronavirus (COVID-19) pandemic. J Am Acad Orthop Surg. 2020;28(11):436-50. https://doi.org/10.5435/jaaos-d-20-00360 PMid:32304401 